\section{Gallensteine - Diagnostik}

\author{
R. Jakobs, J. F. Riemann \\ Medizinische Klinik C, Klinikum der Stadt Ludwigshafen gGmbH
}

Gallensteine sind in den Industrieländern ein häufiger Befund mit einer Prävalenz von etwa 10\%. Alleine in Deutschland ist also mit etwa 8 Millionen Gallensteinträgern zu rechnen. Wie aus mehreren epidemiologischen Untersuchungen in europäischen Industrienationen ersichtlich ist, steigt die Prävalenz altersabhängig an und erreicht bei über 50-jährigen Frauen etwa $15-40 \%(3,10,16)$.

Gallensteine können nach Lokalisation und Zusammensetzung des Steinmaterials eingeteilt werden. Je nach Steinlokalisation wird zwischen Cholezystolithiasis, Choledocholithiasis (Stein in den extrahepatischen Gallenwegen) und der in Europa seltenen - in bestimmten Regionen Asiens hingegen endemischen - Hepatolithiasis (Steine in den intrahepatischen Gallenwegen) unterschieden.

In unseren Breiten handelt es sich in etwa $80 \%$ der Fälle um so genannte Cholesterin- (genauer cholesterinreiche) Steine. Braune und schwarze Pigment-(Bilirubin-) Steine stehen demgegenüber mit nur etwa $20 \%$ deutlich zurück.

\section{Cholezystolithiasis \\ Pathogenese der Gallensteinbildung und Risikofaktoren}

Die Pathogenese der Gallensteinbildung ist vielschichtig. Drei Faktoren spielen eine entscheidende Rolle: eine erhöhte $\mathrm{Li}$ thogenität der Galle, pathologische Nukleationsmechanismen und eine gestörte Motilität der Gallenblase.

Insbesondere bei Patienten mit Gallenblasensteinen konnte ein erhöhter lithogener Index, definiert als Quotient aus den molaren Konzentrationen von Cholesterin einerseits und Phospholipiden und Gallensäuren andererseits, in der Galleflüssigkeit nachgewiesen werden. Ein Index von über 1 bedeutet eine Cholesterinübersättigung der Galle, damit indirekt ein erhöhtes Risiko der Nukleation von Cholesterinkristallen und zur Gallensteinbildung.

Bei der Entstehung von Pigmentsteinen scheint die Cholesterinübersättigung der Galle keine Rolle zu spielen. Entscheidend ist hingegen ein vermehrter Anfall von unkonjugiertem

\title{
Gallensteine - der konkrete Fall
}

Anamnese und klinischer Befund: Ein 80-jähriger Patient wurde wegen eines seit etwa 3 Wochen bestehenden schmerzlosen Ikterus stationär aufgenommen. Der Mann klagte über Inappetenz, Juckreiz und einen Gewichtsverlust von $3 \mathrm{~kg}$ innerhalb der letzten 14 Tage. Der Stuhl war entfärbt, der Urin dunkel. Bis auf eine chronische Bronchitis nach langjährigem Nikotinabusus bestanden keine Vorerkrankungen.

Bei der körperlichen Untersuchung zeigten sich ein deutlicher Haut- und Sklerenikterus sowie Kratzeffloreszenzen an Stamm und Extremitäten. Die Bauchdecken waren weich und die Peristaltik regelrecht. Bei der Palpation des Abdomens bestand kein Druckschmerz, die rektal gemessene Körpertemperatur betrug $36,5^{\circ} \mathrm{C}$.

Untersuchungen: Laborchemisch standen die Erhöhung von $\gamma$-GT (456 U/1) und alkalischer Phosphatase (972 U/l) sowie eine Hyperbilirubinämie (12,3 $\mathrm{mg} / \mathrm{dl}$ ) im Vordergrund. Die Leukozytenzahlen im peripheren Blutbild sowie das C-reaktive Protein waren normal.

Sonographisch war eine Cholezystolithiasis mit 2 Konkrementen von $12 \mathrm{~mm}$, bzw. $19 \mathrm{~mm}$ bei normaler Gallenblasenwand nachweisbar. Der extrahepatische Gallengang (DHC) war dilatiert auf einen Durchmesser von $13 \mathrm{~mm}$. Im Gallengang war präpapillär eine echoreiche Formation ohne Schallschatten darstellbar, hilusnah eine steinverdächtige Struktur mit einem Durchmesser von 20 $\mathrm{mm}$ mit angedeutetem Schallschatten.

Therapie und Verlauf: Unter dem Verdacht "Verschlussikterus bei Choledocholithiasis« wurde eine endoskopische retrograde Cholangio-Pankreatikographie (ERCP) durchgeführt. Die Papille war sehr prominent im Sinne einer sogenannten Steinpapille bei präpapillär inkarzeriertem Stein. Die primäre Intubation des Gallengangs mit dem Kontrastmittelkatheter gelang nicht. Nach precut-Papillotomie der
Papille mit dem Nadelmesser konnte der DHC selektiv kanüliert werden. Die Papillotomie wurde mit einem Standardpapillotom maximal erweitert. Danach entleerte sich bereits spontan ein Stein von etwa $8 \mathrm{~mm}$ Durchmesser in das Duodenum. Bei der Anfärbung des Gallenganges über einen Ballonkatheter war ein weiteres großes Konkrement im proximalen DHC nachweisbar, das primär nicht zu mobilisieren und daher nicht mit dem Lithotripterkorb einzufangen war. Mittels fluoroskopisch gesteuerter Laserlithotripsie wurde der komplizierte Gallengangsstein weitgehend fragmentiert und die Fragmente anschließend komplett extrahiert. Eine Cholezystektomie wurde abgelehnt.

Der heute 82-jährige Patient ist seit 2 Jahren beschwerdefrei und ohne Anhalt für eine Rezidivcholedocholithiasis bei weiterhin nachweisbarer asymptomatischer Cholezystolithiasis.

Dr. Ralf Jakobs, Prof. Dr. J.F. Riemann, Ludwigshafen 